\title{
ELECTRONIC BEHAVIOUR MAPPING AND GIS APPLICATION FOR STAVANGER TORGET, NORWAY
}

\author{
DANIELA MÜLLER-EIE ${ }^{1}$, MONICA REINERTSEN $^{1} \&$ ERLEND TØSSEBRO $^{2}$ \\ ${ }^{1}$ Department of Industrial Economics, Risk Management and Planning, University of Stavanger, Norway. \\ ${ }^{2}$ Department of Electrical Engineering and Computer Sciences, University of Stavanger, Norway.
}

\begin{abstract}
In Norway, there is a growing interest in urban life as opposed to previously urban space. For urban planners and designers this means that methods of spatial registration and analysis need to be extended to include user behaviour, perception and experience. Therefore, user observation and behavioural surveys have become more prominent. To this end, behaviour mapping can be used as a tool to investigate the current use of a space. While manual behaviour mapping has limitations, this paper describes the development and testing of a GIS-based application using electronic maps for registration and analysis of observed behaviour in an urban public space. The behaviour mapping application has been tested and used in a study of Stavanger Torget, the most central public space in Stavanger, Norway. The collection and analysis of data was executed to investigate the amount of users and types of activities in the space throughout the week. Here, the electronic map application proved to be helpful in terms of making registration more efficient, instantly generating digital maps of the observations and providing tabular data for further analysis. This strongly improves urban analysis with regard to behavioural observation and makes related data collection and analysis much more efficient. This ultimately allows for the creation of a GIS database regarding the relationship between physical characteristics and user behaviour, something that is particularly relevant with the growing awareness for quality in public space and urban life.
\end{abstract}

Keywords: behaviour mapping, electronic mapping, GIS, urban public space, usage-spatial relationship.

\section{URBAN RESILIENCE AND CLIMATE CHANGE}

There is a growing interest in the quality of urban public space, not only as an aesthetic and functional entity, but also as a framework for user activity. This more anthropocentric view of evaluating urban space and its use is part of a growing focus on quality in urban environments and liveability.

Urban public spaces normally fulfil several functions, such as civic representation, social and cultural gathering, commercial activity and recreation, and are used by many inhabitants of the city. They therefore undergo much scrutiny. This is also the case in Stavanger, where Torget, the most central public space, has received much criticism in recent years. A deeper investigation of the space's functionality, quality and use is therefore important. However, when investigating the quality and use of public space in relationship to spatial characteristics, it is important to rely on empirical data about spatial and functional aspects as well as understanding user behaviours and needs.

The method of behaviour mapping is well-established within environmental psychology, landscape architecture and urban design [1] and has previously been used to illustrate the impact of the physical environment on human behaviour. While this is a reliable source of information, the collection of data is time-consuming and difficult. New approaches to integrate digital registration on electronic maps, geographic information systems (GIS) and spatio-behavioural analysis are therefore worth investigating. Not only they can provide more efficient data collection and analysis, they can also lead to a better understanding of the theoretical relationship between physical characteristics and human behaviour. 


\section{BEHAVIOUR MAPPING}

The main concern of investigations using behaviour mapping is often to see "who is doing what, with whom, where and for how long?' $[1,2]$. While many studies are concerned with outdoor public space [1-5], it is also possible to use this tool indoors (i.e. in public buildings such as hospitals, or private spaces such as cafes) [5]. Post-occupancy studies of public spaces $[1,2]$ often use this method to uncover whether predicted use coincides with actual use. Thus a main concern of behaviour mapping is whether or not a space is used as intended, i.e. the concurrence between the 'potential environment' and the 'effective environment' (Gans, 1968 in Ref. [3]). While design disciplines often tacitly assume that certain physical environments can manipulate the likelihood of certain behaviours, empirical evidence about this relationship, its nature and strength, is still lacking [2]. Golicnik [2] has investigated this usage-spatial relationship with the help of behaviour mapping and suggests creating a better empirical database for design decision making with the help of new means of recording behaviour. Thus, access to information about the relationship between space and behaviour (e.g. through open-access GIS data) is important for strong design decisions. Such a knowledge base could contribute to urban design theory in general, as well as better practice of creating spaces that generate intended use. Rigorous analysis of existing spaces in terms of their potential and effect (e.g. post-occupancy evaluation) also becomes possible.

Thus, GIS tools and other means of digital mapping can help to provide for better empirical registration and analysis, which helps to explore the relationships between physical attributes and human behaviour further.

\subsection{Urban space and urban life}

While design disciplines are often preoccupied with the physical and aesthetic expression of spaces, the focus on spatial perception and user experience is more prominent in disciplines such as environmental psychology. However, these concepts of urban space on one side and urban life on the other are heavily interwoven, with the first being the prerequisite as well as a designator of quality for the latter. In fact, the quality or success of an urban space is often measured in how much activity it generates [6]. While urban space and its components is a physical concept that can be easily described and analysed through spatial analysis, the definition of urban life is less clear. Reinertsen [4] defines urban life with the help of a literature study [6-9] as the combination of how many people are staying how long in an urban space (activity level), the different types of activity that occur (walking, sitting) and who does what (children, adults). Urban life is also heavily influenced by when it happens (time of day, week day, month) and under which external influences (weather, special events).

Early advocates of the relationship between urban space and urban life have long promoted that only good urban spaces can provide for strong urban life [10, 11]. Now several Norwegian city governments are developing particular interest in the topic. Among them Oslo municipality, where Gehl architects conducted an urban life study in 2014 [12] based on which the municipality, has produced a 'Handbook on urban life in Olso city centre' [13]. It becomes clear that, while urban space and its quality are factors for urban life, urban life spans wider into the economic, cultural and political realms [13].

This increasing interest in urban life also demands alternative approaches that allow registering, documenting, representing and analysing activities and behaviours in urban space. Thus, behaviour mapping as a viable method needs to be applied, further developed and appropriated. 


\subsection{Preparation and registration}

The process of behaviour mapping usually starts with a base map of the space under investigation. It is important to pick a relevant scale, both in terms of level of detail for registration as well as the practicality of handling a large printed map. It is also important to clearly identify the boundaries of the study area, which sometimes means that a large area must be divided into several smaller spaces $[1,14]$. Traditionally the initial registration of behaviours is undertaken manually; i.e. the principal observer marks subjects and their activity on a paper map by hand (Fig. 1). This information is later on transcribed to digital maps (Fig. 2) [1-3, 5, 14].

Registration duration usually depends on the amount of observed behaviour, i.e. how many people are occupying the investigated space. In public spaces, the registration period is usually limited to 5-15 minutes due to large numbers of occupants $[1,4,5]$. This is particularly true for registration on paper, since observed subjects are marked on top of each other, which can lead to cluttered observation sheets. The frequency and number of observations largely depends on what the scope of the study is. To control for other factors, such as weather, time of day, day of week or time of year, it is necessary to repeat observations several times.

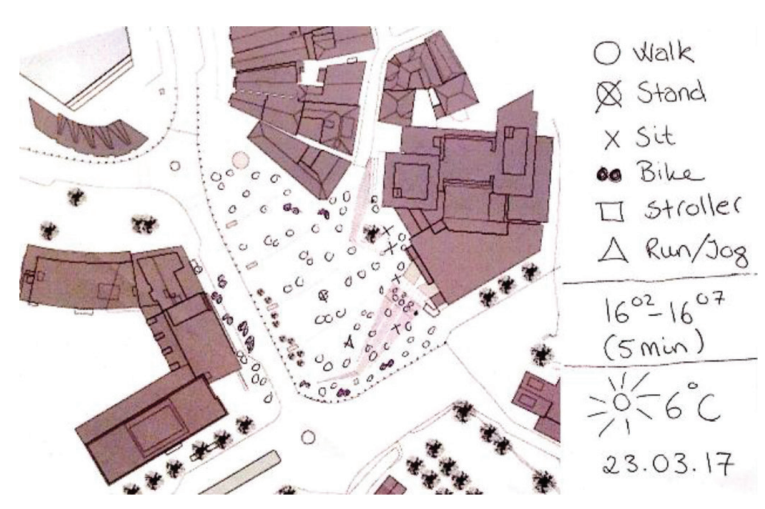

Figure 1: Manual behaviour mapping (Reinertsen, 2017).

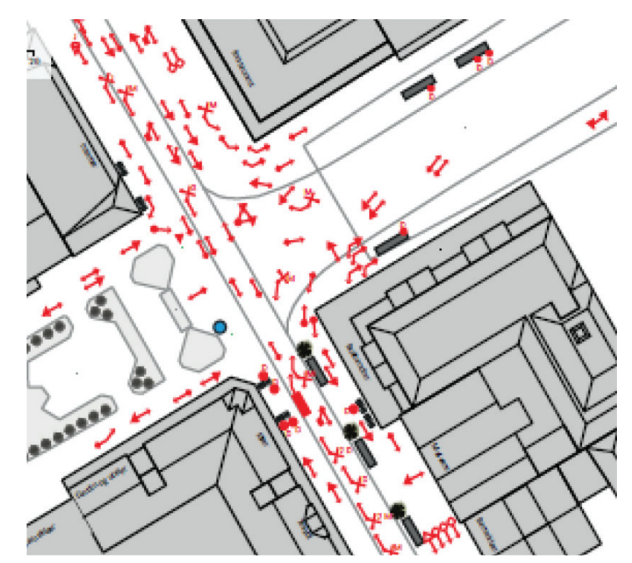

Figure 2: Graphic representation of geographic data from behaviour mapping (Madsen, 2015). 


\subsection{Observed activities}

The type of investigated behaviours also depends on the purpose of the study. Some studies aim at registering the amount of certain activities, while others are interested in changes of behaviour on different times of the day or week. But the main concern is usually to capture different types and duration of behaviour, i.e. to which degree certain physical environmental cater to desired recreational activities, such as sitting down [1], socialising, resting, playing [14] and skating [2, 3].

Figure 3 shows an example of the range of behaviours and activities that can be observed, ranging from walking, cycling, standing and other likely activities to occur in public space. In this particular case [5] the behaviours were divided into the categories of behaviour introduced by Gehl [15]: necessary, optional and social. When observing play areas, the quality of activity might be more of interest, e.g. the intensity of physical activity [14]. However, the legend setup used should always allow for registration of unexpected behaviour [2]. Such flexibility might be easier to achieve with manual registration, which is why, even when registering behaviour in electronic maps, researchers have used paper notes in addition [4].

\subsection{Graphic representation and data analysis}

The collected data can be represented both geographically (in maps) as well as statistically (in graphs). As shown in Figure 2, all people occupying the studied space and their activities are simultaneously displayed on the map. This convenient and effective way of conveying geographic data is paramount to understanding the effect of physical elements, particularly for design disciplines who are very familiar with the mapping of data.

Furthermore, the collection of data with behaviour mapping allows for numeric analysis giving information about the amount of occupants, the relative weighing of displayed behaviours as well as duration. Figure 4 for instance shows the level of occupation of Stavanger Torget at different times of the day throughout one week, without displaying the different types of activities [4].

Aside from the practical issues (exposed to weather, short observation intervals, timeconsuming transcription of manual data into digital maps) behaviour mapping as a method, has also other challenges. Particularly in busy environments, subjects moving around quickly are at risk of being registered several times or not at all $[4,5,14]$, thus leading to an

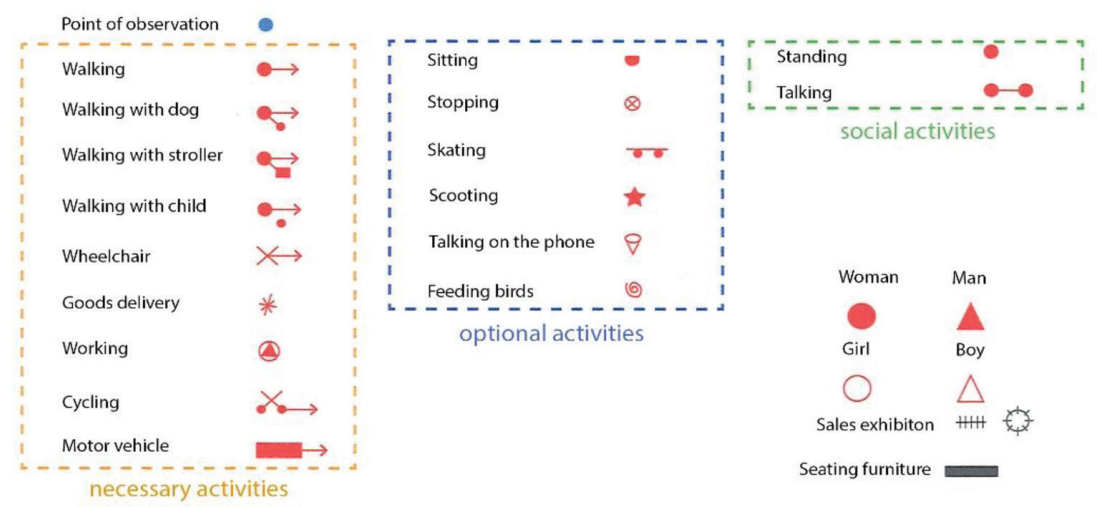

Figure 3: Legend showing different activity symbols for behaviour mapping (Madsen, 2015). 
THE WEEK: 20.03.17- 26.03.17

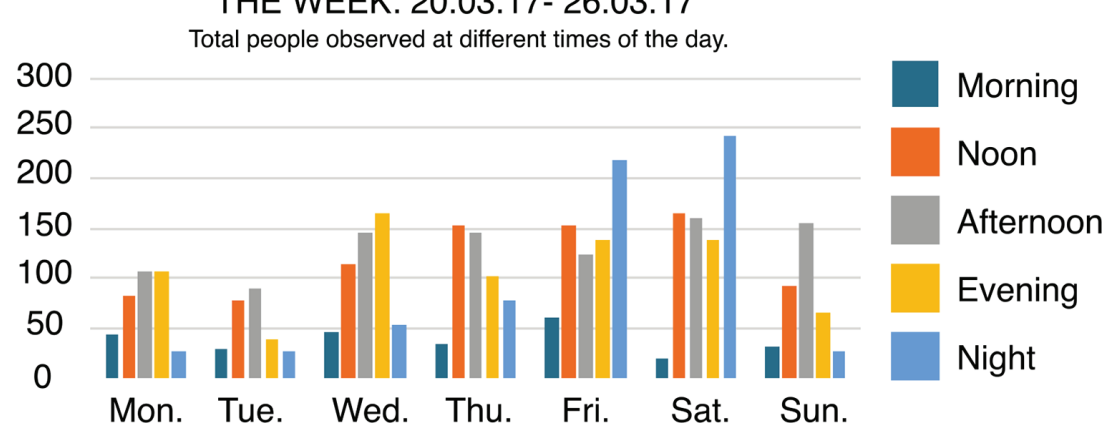

Figure 4: Graphic representation of numeric data from behaviour mapping (Reinertsen, 2017).

over-registration of slower activities and long-term occupation. In addition, subjects often execute several activities at once (e.g. standing and talking), which makes it difficult for the researcher to select the dominant behaviour. Furthermore, all subjects using the spaces are displayed simultaneously in the resulting maps, which does not allow portraying movement or dynamic changes in spatial occupancy.

While the first steps of digitalising spatial-behavioural observations are already taken [14], it is obvious that the development of small handheld devices in recent years and the further integration of GIS into urban planning and design contribute to making the described method more efficient [2, 14]. Using electronic maps for registration can allow geographic as well as numeric data to be displayed instantaneously. In addition, analysis with the help of, e.g. ArcGIS, can be advantageous in terms of developing databases for spatial-behavioural data. Thus, the development of a GIS-based electronic behaviour mapping application is key for efficient and convenient use of this method.

\section{ELECTRONIC REGISTRATION AND GIS APPLICATION}

In order to do behaviour mapping using a computer, the computer has to be small and portable so that the researcher can bring it easily to the site. For outdoor behaviour mapping it also needs to withstand some rain and be legible in the sun. For fast registration of positions and movements of people, a touch screen is better than a laptop mouse. For these reasons, it was decided to focus development of the electronic map application on tablets rather than on laptop computers. The 'behaviour mapper' used in this project is an iPad app developed by two bachelor students in computer science [16]. The iPad is a commonly used tablet with a standardised shape, which makes it easier to develop an easy-to-use application on this platform than on the Android platform. However, it is possible to develop the same type of application for Android or for Windows-based tablets.

When using the 'behaviour mapper', the user has to first tap on the symbol representing the type of behaviour to register, then tap on the position of the person, and if necessary drag the finger in the direction the person is moving. Paper maps quickly become cluttered when registering many people while the behaviour mapper remains fairly clear (Fig. 5). The app can also be configured to only show the last ten people registered. The 'behaviour mapper' allows the user to define which symbols to use and which map to use as background. The system also allows adding additional symbols during mapping. For the background map, either an image stored on the tablet or a map generated by Google Maps can be used. Google Maps is 


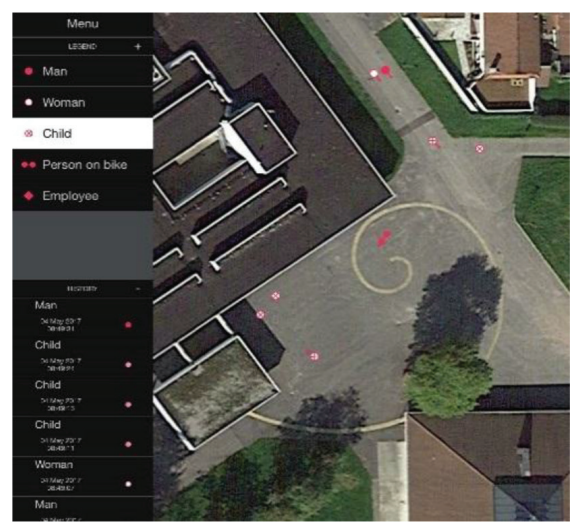

Figure 5: Mapping screen of the 'behaviour mapper' (Sørensen \& Vier, 2017).

\begin{tabular}{|c|c|c|c|c|}
\hline Time & Position & Angle in degrees & Note & Type \\
\hline 04/05/2017, 23:21 & (688.0. 500.5) & 999.0 & & Sitting adult \\
\hline 04/05/2017, 23:21 & $(709.5,508.0)$ & 999.0 & & Sitting adult \\
\hline 04/05/2017, 23:21 & $(682.0,546.0)$ & 999.0 & & Sitting child \\
\hline 04/05/2017, 23:21 & $(617.0,578.0)$ & 999.0 & & Sitting child \\
\hline 04/05/2017, 23:21 & $(670.5,568.5)$ & 999.0 & & Sitting child \\
\hline 04/05/2017, 23:21 & $(326.0,142.0)$ & -90.0000025044782 & & Adult \\
\hline 04/05/2017, 23:21 & $(166.0,187.0)$ & 5.27389598979267 & Stopped and talked on phone & Adult \\
\hline 04/05/2017, 23:21 & $(44.0,290.0)$ & 10.3663223910746 & & Person on bike \\
\hline 04/05/2017, 23:21 & $(605.0,729.0)$ & 125.469878373839 & & Person on bike \\
\hline 04/05/2017, 23:21 & $(499.0,577.0)$ & 129.05848708452 & & Person on bike \\
\hline $04 / 05 / 2017,23: 21$ & $(743.0,208.5)$ & -110.840917737803 & Left the same way & Person running \\
\hline 04/05/2017, 23:21 & $(142.0,315.0)$ & 18.2324898949591 & & Person running \\
\hline 04/05/2017, 23:21 & $(467.5,212.5)$ & 999.0 & & Adult \\
\hline 04/05/2017, 23:21 & $(522.5,245.5)$ & 999.0 & & Adult \\
\hline 04/05/2017, 23:21 & $(467.0,246.0)$ & 999.0 & & Adult \\
\hline 04/05/2017, 23:21 & $(129.0,405.0)$ & 999.0 & & Child \\
\hline 04/05/2017, 23:21 & $(567.0,291.5)$ & 999.0 & & Sitting adult \\
\hline
\end{tabular}

Figure 6: Data imported to spreadsheet software (Sørensen \& Vier, 2017).

free to use in this context as long as the user is non-commercial and the user does not download too many maps. An alternative to Google Maps would be Open Street Map, which is free to use for anyone.

To exported data from the app, a CSV (Comma-Separated Values) file can be generated. This file can be send by email, stored in the apple cloud, or opened in a spreadsheet. Most spreadsheets, including Excel, can open CSV files, which allows for quick representation of numeric data. The CSV files contain a table with one line per registered person. This line contains time, position, angle of motion, notes made in the app, behaviour type description and behaviour type number (Fig. 6). Time is as registered by the device when the entry is created, so it is important that the device has a correct internal clock. Position is measured in pixels relative to the picture used as a background. In order to import the entries into ArcGIS or other GIS software, these coordinates need to be converted to map coordinates. The current app does not do this but it is technically possible as long as you know the map coordinates of the corners of the image. When using a background map from Google Maps or Open Street Map, it is possible to obtain map coordinates for the corners when creating the background map. When using an image as a background map, these coordinates must be provided by the user. The behaviour type number may be used to set the symbol that ArcGIS uses to display the data.

The 'behaviour mapper' was successfully tested during the registration of behaviour on Stavanger Torget in March 2017. This first field test provided feedback and led to a number of improvements, such as registration symbols.

\section{ELECTRONIC BEHAVOUR MAPPING AT STAVANGER TORGET}

Torget is Stavanger's most central public space and has a long history. In 1999, it was decided that the space would be renewed and be a part of Stavanger's millennium site. The new Torget was finished in 2008. Ever since, there has been a lot of controversy about it [17, 18]. These debates are ongoing and strongly influenced by emotions. Criticism includes statements about the space being empty of people and lacking urban life.

Stavanger Torget is a large open space stretching from Stavanger cathedral to the quayside on a north-facing slope (Fig. 10). On the east, large stairs meet the surrounding buildings and 
stretch far into the space itself (Fig. 7). On the west, there is a road separated by bollards. The surface is covered with large stone slabs and there are four linear indents for water drainage running from west to east ending in stone fixtures that can be used as an informal sitting space. There is also a seating area on the east-side (Fig. 8) and a tidal fountain.

The main goal of the study was to establish whether and how Stavanger Torget is used, both under everyday conditions and larger events [4]. The use of behaviour mapping was chosen to create empirical data that can contribute to the on-going debate about the space's functionality.

\subsection{Data collection}

The application 'behaviour mapper' was used to register eight different behaviours (Fig. 9) to study how many people occupied the space at any given time during the fieldwork. The registration was conducted for one week in March (20th to 26th march 2017) with respectively five registrations each day $(8: 00,12: 00,16: 00,20: 00,0: 00)$. The observations periods typically lasted five minutes during which 20 to 243 people were observed [4].

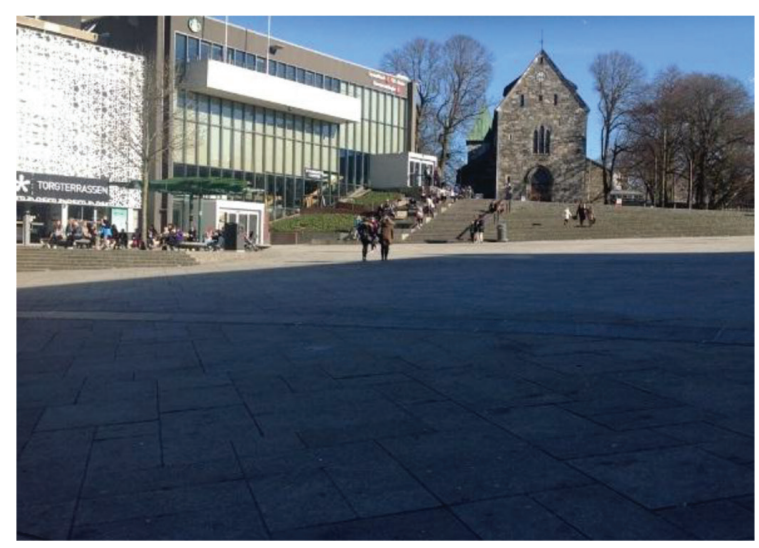

Figure 7: North-west view of Stavanger Torget with cathedral (Reinertsen, 2017).

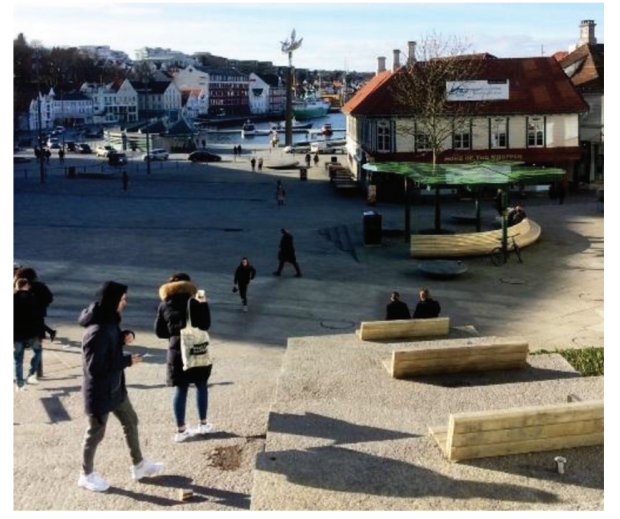

Figure 8: South-east view of Stavanger Torget sloping to the quay (Reinertsen, 2017). 


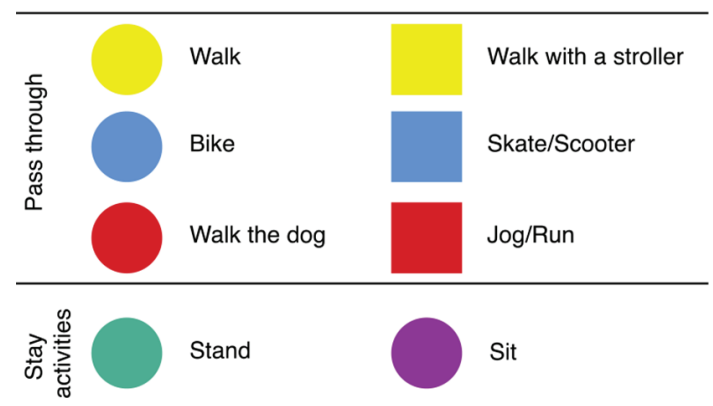

Figure 9: Categories of behaviour used in 'behaviour mapper' (Reinertsen, 2017).

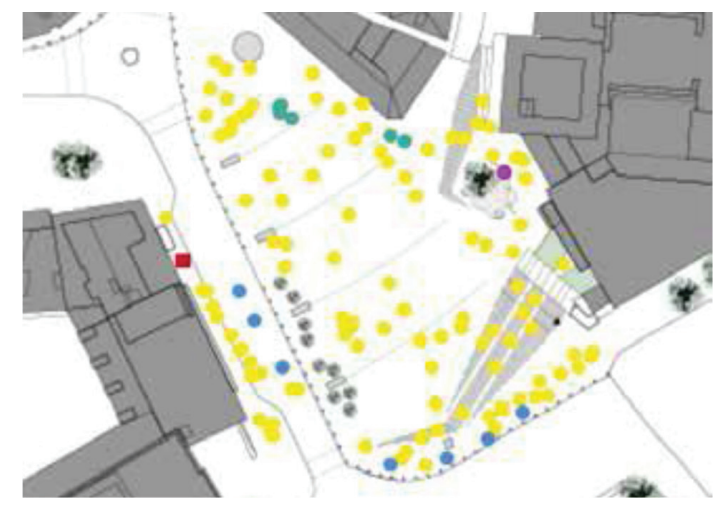

Figure 10: Behaviour map generated by 'behaviour mapper’ (Reinertsen, 2017).

A specially prepared base map was chosen instead of an online map service, due to the necessary level of detail. The 'behaviour mapper' immediately produced output maps (Fig. 10) and numeric data were used to present activity types (Fig. 12).

\subsection{Analysis and results}

The results from the study combine findings from the observations, behaviour mapping and spatial analysis, i.e. both urban space and urban life.

As Figure 12 shows $90 \%$ of people were passing through Stavanger Torget, meaning there is a big potential to make more people stay or sit down. However, the study also revealed that Stavanger Torget was used by many people at all times during the week (Fig. 4), revealing some of the strong criticism as unjustified. Looking at spatial-behavioural relationships, the produced maps (Fig. 11) illustrate that long-term occupation (staying, sitting) generally occurred more at the edges of the space [4]. Since Stavanger Torget has unclear boundaries in the north and south, edges are lacking creating a diffuse public space without human scale. In everyday conditions the large size and openness are challenging, and creating smaller spaces within the big space would be advantageous. Torget currently has 22 places for temporary stalls that could be used to do this for instance with sales stand or food trucks. For large events, however, the big space is an advantage as it allows the gathering of many people and provides good vantage points due to its sloping terrain. 


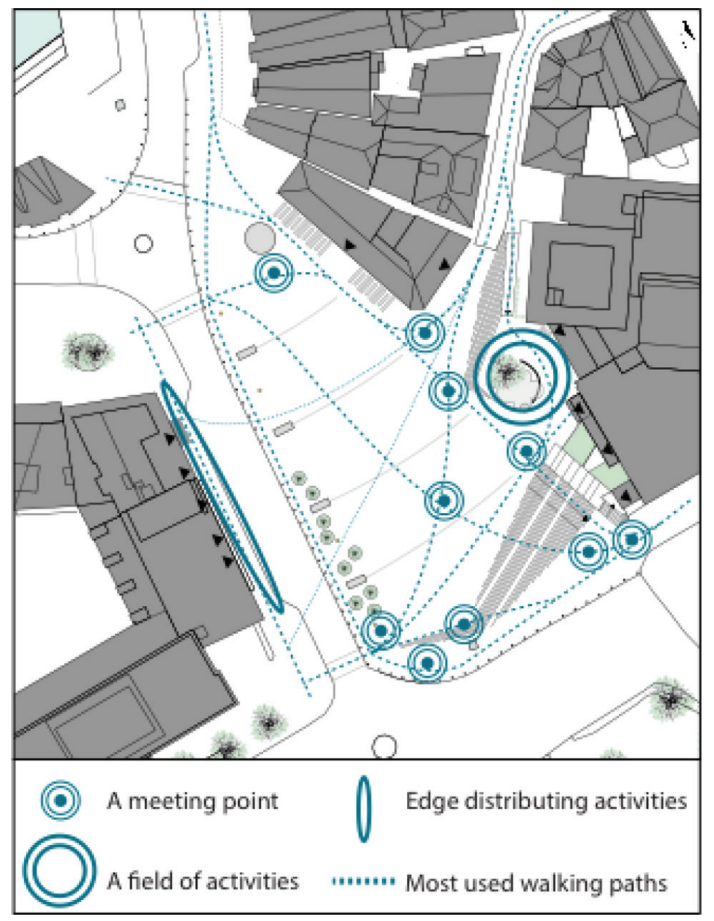

Figure 11: Spatial areas of behavioural clusters at Stavanger Torget (Reinertsen, 2017).
THE WEEK: 20.03.17- 26.03.17
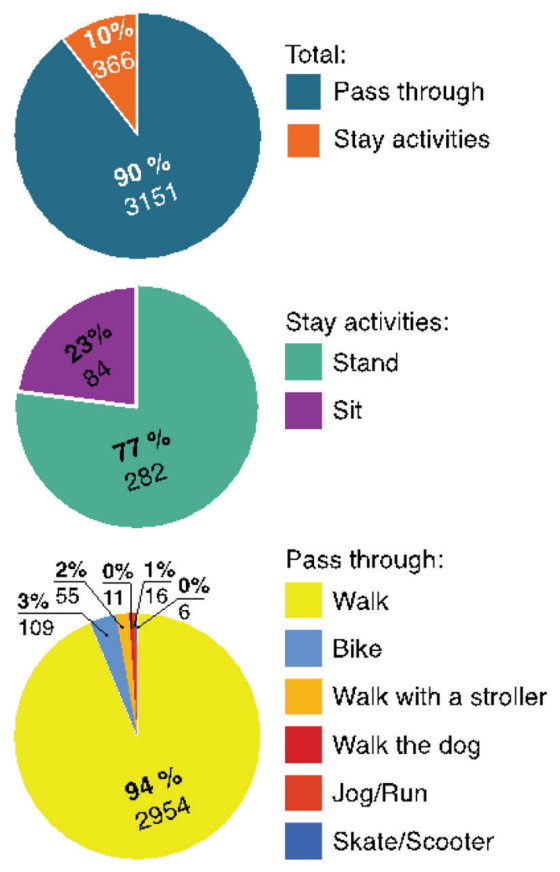

Figure 12: Types of activity throughout the week (Reinertsen, 2017).

The analysis also shows that the formal sitting places with backrest are used most often, while the informal sitting places, which are used most often, are the stairs. Other possible informal sitting places, such as the tidal fountain and stone fixtures, were intended as secondary seating but were not observed being used as such. Even though the water indents and the tidal fountain were supposed to function as artistic points of interest, the behaviour mapping could not confirm this. Thus, the space might be lacking a focus element, giving people a reason to stop. In the evening, however, the floor surface is illuminated with different patterns that act as an interesting aesthetic element. Observations showed that this illumination triggered spontaneous activity and people stopped to watch.

It is important to notice that there were people all day all week regardless of the weather. While good weather contributes to higher occupation, a bench with a roof enables people to sit at any time, which some did during the study period. The weather is therefore not exclusively decisive for whether people are sitting down, but the quantity and duration of occupation are weather-dependent. Regardless of weather, Friday and Saturday night seemed to show most activity, largely resulting from people having midnight snacks here.

The behaviour mapping at Stavanger Torget thus contributes to correcting the perception that this space is devoid of urban life. While there is a strong potential for improving the space, urban life could be increased without substantial and costly physical interventions. Some of the criticism addressed the high costs, and therefore, an example for how Stavanger Torget can be improved is to introduce temporary measures and studying their effect (with behaviour mapping) before making them permanent. 
The lack of people occupying Stavanger Torget over a longer period indicates that the space does not provide for potential activity and might also lack human scale as a prerequisite for such. This confirms that the quality of a space cannot be merely measured in the number of people using it, but a more qualitative approach is necessary to understand the duration and nature of occupation.

\section{DISCUSSION}

Given the presented case study of Stavanger Torget, behaviour mapping is a relevant and efficient way of contributing to empirical evidence regarding the theoretical relationship between spatial attributes of urban public space and human behaviour. Additionally, the empirical data generated can actively contribute to future design decisions.

The results of the behaviour mapping at Stavanger Torget also indicate that the behaviour mapper' is a helpful application for registering behaviour in urban public spaces. Being able to directly register observations on an electronic map, makes the registration process more convenient and renders the off-site transcription into digital maps redundant. Thus, the collected geographic information can be displayed immediately after registration on-site. This is particularly helpful since design disciplines are used to processing spatial information in maps. Further, the visually simple and uncluttered registration makes it easy to handle large amounts of data quickly, allowing for longer periods of registration. It then becomes more convenient to describe the collected data statistically as well as searching for explanatory factors with the help of statistical correlations.

Particularly with the possibility to integrate the collected data with GIS software such as ArcGIS, it is possible to visualise and re-categorise data in order to explore the spatial-behavioural relationship in more general terms. Thus, the provision of a larger database relating certain environmental characteristics and certain activities is extremely valuable for the design disciplines. For further exploration of electronic registration of behaviour mapping and its potential application as GIS, it would be interesting to explore possibilities for in-situ registration of polylinear movement patterns. A smoother integration with ArcGIS should also be further investigated.

This article is based on the work of Alexander Wiig Sørensen and Espen Stuvik Vier, two bachelor students in computer science at UiS, and Monica Reinertsen, a master student in urban development and design at UiS in 2017. Many thanks for their permission to use their work. Other illustrations of behaviour mapping are reproduced with friendly permission from Åslaug Madsen, a master graduate in urban development and design at UiS in 2015.

\section{REFERENCES}

[1] Francis, M., Koo, J. \& Ramirez, S., Just a comfortable place to sit: Davis sittable space study. Department of Environmental Design, University of California, Davis, 2010. https://doi.org/10.13140/RG.2.1.4434.6321

[2] Golicnik, B., GIS behaviour mapping for provision of interactive empirical knowledge, vital monitoring and better place making. in Urban Sustainability Through Environmental Design-Approaches To Time-People-Place Responsive Urban Spaces, K. Thwaites, S. Porta, O. Romice, and M. Greaves, Eds. Oxon: Routledge, 2007.

[3] Marusic, B.G., "Analysis of patterns of spatial occupancy in urban open space using behaviour maps and GIS," Urban Design International, 16(1), pp. 36-50, 2011. https://doi.org/10.1057/udi.2010.20 
[4] Reinertsen, M., The city's main square in everyday life - a casestudy of Torget in Stavanger. Master thesis, IØRP, UiS, unpublished, 2017.

[5] Madsen, A., The Impact of Shopping Malls on Smaller Towns - A Case Study of Svortland and Hellvik Mall. Master thesis, IØRP, UiS, 2015.

[6] Gehl, J., "Byer for mennesker," 2010.

[7] KMD, "Byrom - En Idehåndbok," Kommunal- og Moderniseringsdepartmentet, Oslo2017.

[8] Butenschøn, P., Folk på gaten i Norske gater og plasser. ed: Oslo: Forlaget Press, 2012.

[9] Montgomery, C., Happy city: transforming our lives through urban design. Macmillan, London, 2013.

[10] Whyte, W.H., The social life of small urban spaces. The Conservation Foundation, Washington, DC, 1980.

[11] Gehl, J., Livet mellem husene: udeaktiviteter oy udemiljøer. Arkitektens forlag, 1987.

[12] Architects, G., Bylivsundersøkelse Oslo sentrum. Olso Kommun, Olso, 2014.

[13] (2017). Handlingsprogram for Økt Byliv i Olso Sentrum.

[14] Cosco, N.G., Moore, R.C. \& Islam, M.Z., Behavior mapping: a method for linking preschool physical activity and outdoor design. Medicine \& Science in Sports \& Exercise, 42(3), pp. 513-519, 2010. https://doi.org/10.1249/mss.0b013e3181cea27a

[15] Gehl, J., Three Types of Outdoor Activities. In The Urban Design Reader, M. Larice \& E. Macdonald, (Eds.). The Routledge Urban Reader Series, Oxon: Routledge, 2007.

[16] Sørensen, A.W. \& Vier, E.S., Behaviour Mapper - a tablet application for behaviour mapping. Bachelor thesis, IDE, UiS, unpublished, 2017.

[17] Jupskås, S.H., "Torget blir forsinket igjen - Stavanger Tusenårsstedet. ," in Stavanger Aftenblad, ed. Stavanger, 30.03.2016.

[18] Grimnes, P., "Jeg er luta lei av den årelange hetsingen av Torget," in Stavanger Aftenblad, ed. Stavanger, 01.04.2017. 